\title{
Effect of needle insertion depth and apical diameter on irrigant extrusion in simulated immature permanent teeth
}

\section{Hacer AKSEL \\ Sevinc ASKERBEYLI Cigdem CANBAZOGLU Ahmet SERPER}

Department of Endodontics, Faculty of Dentistry, Hacettepe University, Ankara, Turkey.

Declaration of Interests: The authors certify that they have no commercial or associative interest that represents a conflict of interest in connection with the manuscript.

Corresponding Author:

Hacer Aksel

E-mail: hacer.yilmaz@hacettepe.edu.tr

DOI: 10.1590/1807-3107BOR-2014.vol28.0053

Submitted: Apr 02, 2014

Accepted for publication: Jun 27, 2014

Last revision: Aug 22, 2014

\begin{abstract}
The aim of this study was to compare the amount of irrigant extrusion in simulated immature permanent teeth when the apical diameter and needle insertion depth were varied. Thirty single-rooted maxillary incisors with straight root canals were selected. The root length was standardized to a length of $9 \mathrm{~mm}$. The teeth were divided into two experimental groups according to the degree of apical enlargement $(n=15)$. The apices were enlarged to a diameter of $1.10 \mathrm{~mm}$ or 1.70 $\mathrm{mm}$ by using a \#3 or \#6 peeso reamer, respectively, to simulate immature teeth. The irrigation solution was applied 2 or $4 \mathrm{~mm}$ short of the working length (WL) in each experimental group. The glass vial model was used for the collection of extruded irrigant beyond the root apex. A two-way repeated measures analysis of variance test showed that there was no significant difference between different needle insertion depths (2 and $4 \mathrm{~mm}$ short of the $\mathrm{WL}$ ) in the group with an apical diameter of $1.70 \mathrm{~mm}(p>0.05)$. In the group with an apical diameter of $1.10 \mathrm{~mm}$, a $32 \%$ increase in irrigant extrusion was observed when the needle was positioned at $2 \mathrm{~mm}(p<0.05)$. Regarding the effect of apical diameter, the group with a diameter of $1.70 \mathrm{~mm}$ showed more apical extrusion of the irrigant (34\% increase for the needle positioned at $2 \mathrm{~mm}$ and $68 \%$ increase for the needle positioned at $4 \mathrm{~mm}$ ). It was observed that the needle insertion depth and apical diameter have a significant effect on irrigant extrusion in immature permanent teeth.
\end{abstract}

Keywords: Endodontics; Root Canal Irrigants; Root Canal Preparation.

\section{Introduction}

The main purpose of root canal treatment is to prevent or treat apical periodontitis. ${ }^{1,2,3}$ For the treatment of immature permanent teeth, the goal is to restore the original physiologic structure and function of the pulp-dentin complex. However, the treatment of necrotic immature teeth has always been a clinical challenge for several reasons. ${ }^{4}$ Primarily, it is difficult to achieve an appropriate apical seal with an open apex by performing a conventional root canal treatment. In addition, the suspended development of dentin after pulpal necrosis can result in thin dentinal walls that make the tooth more prone to fracture.

Revascularization is a valuable treatment for necrotic immature permanent teeth. The key procedures of this regenerative protocol require minimal to no instrumentation of the canal and rely on a gentle but thorough irrigation 
of the root canal system. Therefore, the disinfection of the root canal only depends on chemical disinfection. $2.5-6 \% \mathrm{NaOCl}$ has been used for irrigation and disinfection during regenerative endodontic therapy., ${ }^{5,67,7,9} \mathrm{~A}$ modification to the final step of this protocol by irrigating with EDTA has been recommended to optimize the conditions for cellular differentiation, tissue formation, and regeneration. ${ }^{10,11}$ However, inadvertent irrigant extrusion toward the periapical tissues has been reported in a number of case studies. ${ }^{12,13,14}$ Sequelae such as severe pain, burning sensation, inflammation, and possible delayed healing may develop, depending on the type of irrigant used. ${ }^{14,15}$ In addition, the root canal disinfection material can be detrimental to stem cells. ${ }^{11}$ The preservation of the remaining dental pulp stem cells and mesenchymal stem cells of the apical papilla (SCAPs) is an important prerequisite in root canal revascularization and the completion of root maturation. ${ }^{16}$ Although case reports have been published with successful outcomes related to regenerative endodontics, there is still no standardized treatment protocol.

Psimma et al. ${ }^{17}$ reported that irrigant extrusion decreased as the needle moved away from the working length with increasing apical size. However, in that study, the apical size was enlarged to a \#35 size. To date, irrigant extrusion in immature permanent teeth has not been thoroughly studied in the literature. For this reason, the purpose of this study was to evaluate irrigant extrusion in simulated immature permanent teeth when the apical diameter and needle insertion depth varied.

\section{Methodology}

Thirty extracted human single-rooted maxillary incisors were used. All experiments were performed under a protocol approved by the Human Subjects Ethical Review Committee of Hacettepe University (Project No: GO 14/69).

\section{Preparation of the specimens}

The criterion for tooth selection was a lack of visible root caries, fractures or cracks upon examination under a stereoscopic microscope at $\times 32$ magnifications. The tooth length was standardized to $16 \mathrm{~mm}$ by removing excess crown structure perpendicularly to the tooth axis, and the root length was stan- dardized to a length of $9 \mathrm{~mm}$ as measured from the facial cemento-enamel junction (CEJ). The WL was set to $0.5 \mathrm{~mm}$ shorter than of the tooth length measurement. Measurements of the samples were performed with a digital caliper.

Following conventional access cavity preparation, the root canals were prepared using ProTaper NiTi instruments (Dentsply Maillefer, Ballaigues, Switzerland). Each root canal was irrigated with $2 \mathrm{ml}$ of distilled water between successive instruments. At the end of instrumentation, the root canal was irrigated with $10 \mathrm{ml}$ of distilled water. The root canals were dried with paper points, and the external surfaces of the specimens were dried by air blast. All specimens were stored at $100 \%$ relative humidity during the experimental period.

\section{Experimental procedures}

Each tooth was mounted up to the CEJ through a pre-cut hole into the lid of a $10 \mathrm{ml}$ glass vial with self-curing acrylic resin, so that its longitudinal axis was parallel to and as close as possible to the vial axis. Each root surface was covered with cyanoacrylate (Catalog \#41032, Forakim, Ankara, Turkey). To simulate teeth with immature apices, peeso reamers were used to enlarge the root apex. In one group, peeso reamers between \#1 and \#3 $(1.10 \mathrm{~mm})$ were introduced into the root canals by allowing them to protrude $1 \mathrm{~mm}$ beyond the apex, while in the other group, the root apex of the specimens was enlarged to the size of a \#6 peeso reamer $(1.70 \mathrm{~mm})$. In each experimental group, the irrigation solutions were applied 2 or $4 \mathrm{~mm}$ short of the WL $(\mathrm{n}=15)$ with a $5 \mathrm{ml}$ disposable plastic syringe and a 27 gauge open-ended needle.

\section{Test apparatus}

A $10 \mathrm{ml}$ glass vial was used to simulate a periapical lesion and accommodate the extruded irrigant (Fig. 1). Each specimen was embedded in a lid and fitted to a vial. Glass vials were entirely filled with a $0.9 \%$ saline solution. A bent 25 gauge needle was placed alongside the lid to use as a drainage cannula and balance the air pressure inside and outside of the vials. 
The extruded irrigant was collected from the needle into a disposable plastic insulin syringe. Experiments were performed three times, and an average score was calculated so that the irrigant extrusion volume could be accurately measured. The volume of the collected irrigant was calculated in $0.1 \mathrm{ml}$ increments, based on the syringe markings. Statistical analysis of the experimental groups was conducted with a two-way repeated measures analysis of variance test $(p=0.05)$.

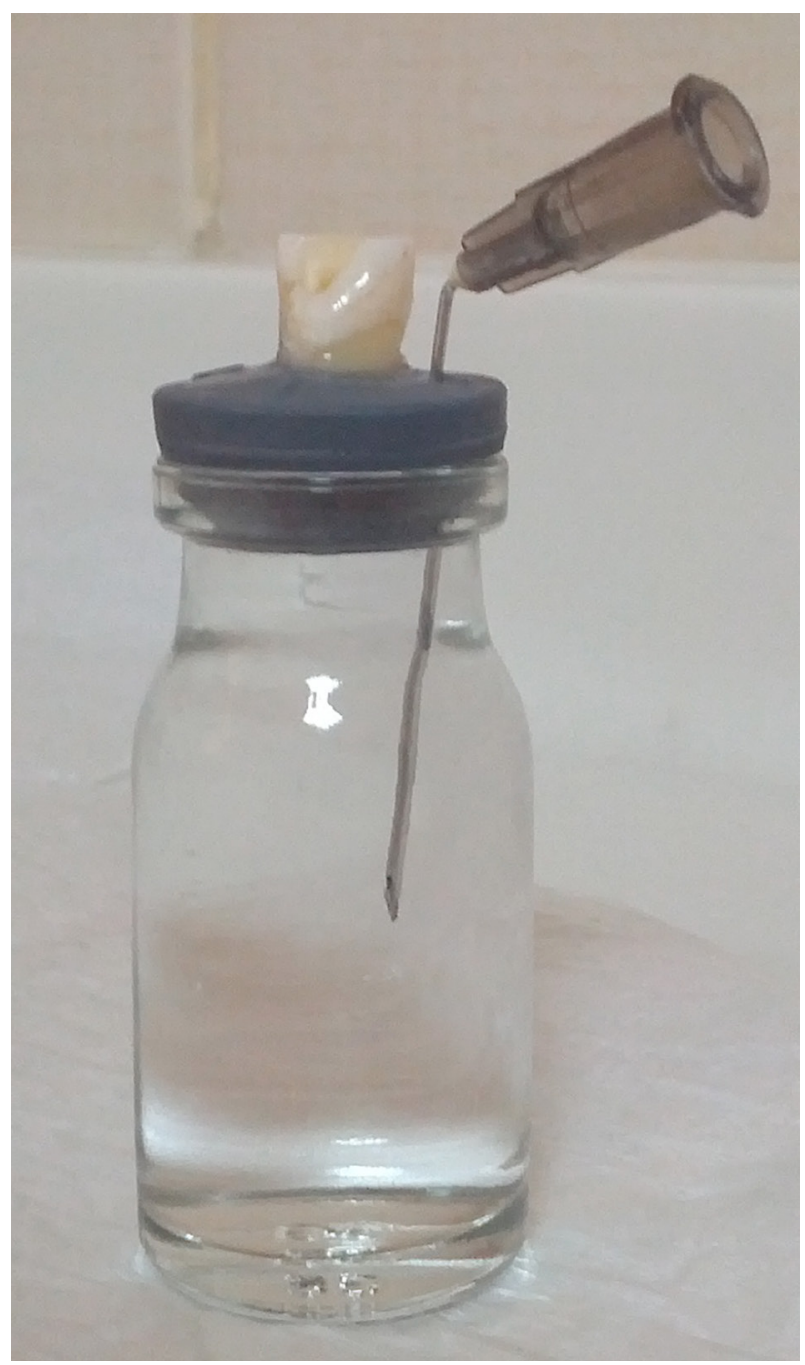

Figure 1. The amount of extruded irrigant

\section{Results}

Statistical analysis revealed no significant difference between different needle insertion depths ( 2 and $4 \mathrm{~mm}$ short from the WL) in teeth with an apical diameter of $1.70 \mathrm{~mm}(0.39 \pm 0.076 \mathrm{ml}$ vs. $0.37 \pm$ $0.074 \mathrm{ml}, \mathrm{p}>0.05)$. In the group with an apical diameter of $1.10 \mathrm{~mm}$, a 32\% increase in irrigant extrusion was observed when the needle was positioned $2 \mathrm{~mm}$ short of the WL than compared to the needle positioned $4 \mathrm{~mm}$ short of the WL $(0.29 \pm 0.039 \mathrm{ml}$ vs. $0.22 \pm 0.070 \mathrm{ml}, p<0.05$, Fig. 2).

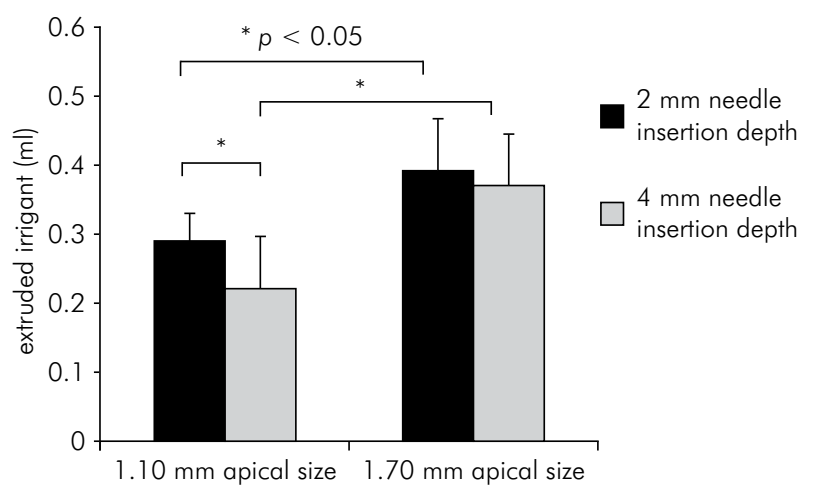

Figure 2. The glass vial model

In a comparison of the effects of different apical diameters, the group with a diameter of $1.70 \mathrm{~mm}$ showed more apical extrusion of irrigant than the group with a diameter of $1.10 \mathrm{~mm}$ (34\% increase for the needle positioned at $2 \mathrm{~mm}$ short of the $\mathrm{WL}$ and $68 \%$ increase for the needle positioned $4 \mathrm{~mm}$ short of the WL, $p<0.05$, Fig. 2).

\section{Discussion}

The main findings in this study were as follows: 1) no significant difference in the amount of apically extruded irrigant was observed when the needle insertion depth changed from 2 to $4 \mathrm{~mm}$ short of the $\mathrm{WL}$ in teeth with a larger apical diameter $(1.70$ $\mathrm{mm}$ ), and 2) there was a tendency to extrude more irrigant as the apical diameter increased.

The instrumentation of root canals may cause irrigant extrusion in small quantities, regardless of the type of instruments used and the preparation technique. ${ }^{14}$ The apical extrusion of irrigants has been studied extensively because of its clinical relevance, particularly because it may cause flare-ups resulting from the introduction of bacteria, pulpal tissue, or irrigating solutions into the periapical tissues. ${ }^{18}$ There have been a wide range of 
studies focused on irrigant extrusion. ${ }^{19,20,21,22,23}$ Many factors affect the amount of irrigant extrusion, including the use of a high flow rate; destruction of the apical constriction due to over-instrumentation or apicoectomy; perforation of the root canal system iatrogenically or from root resorption; wedging of the needle in the root canal; the presence of a periapical lesion, apical fenestration, or horizontal root fracture; insertion of the needle beyond the apical foramen; the volume and concentration of the irrigant used; and intentional extrusion. ${ }^{24}$ However, studies have been limited to teeth with mature root morphologies. For this reason, the observed results should not be generalized to teeth with incomplete root development. Immature necrotic permanent teeth have a wide root canal and apical foramen that allows for rapid transportation of infectious microorganisms to the periapical tissues, causing extensive bone resorption. Thus, the present study specifically focused on factors influencing irrigant extrusion during root canal irrigation of immature permanent teeth. In this study, mature human teeth were modified to resemble immature teeth. Although individual differences are always likely between different teeth, extreme care was taken during the selection and division of experimental teeth into groups. Another option could have been to select immature premolars, which are sometimes extracted for orthodontic purposes. Although these teeth would display the true histological characteristics of teeth with immature apices, this approach was not selected because of the difficulty of obtaining an adequate number of such teeth with similar dimensions.

Nail varnish is typically used to seal the root canal surface to prevent any leakage from the lateral canals or dentinal tubules. In this study, cyanoacrylate was used to seal the entire root surface in place of than nail varnish. Cyanoacrylate is water-resistant and adheres to cementum and dentin much better than nail varnish. Immediately after placement, cyanoacrylate flows easily, similar to a thick, sticky gel. However, within 1-2 hours it hardens similarly to acrylic resin. If cyanoacrylate flows into the canal, it becomes difficult to remove, so before applying it near the apical foramen, the canal should be blocked from the inside with a file or a gutta-percha point.

Various in-vitro methods have been used to simulate periapical tissue resistance during irrigant extru- sion. Several studies have completely neglected the potential effect of periapical tissues by evaluating the amount of extrusion into vials full of air. ${ }^{19,23,25,26}$ This approach results in an implausible situation in which there is no periapical tissue resistance, creating an obvious discrepancy with in-vivo conditions because the presence of an apex surrounded by ambient air is unlikely. This issue has been identified by previous studies as causing an overestimation of irrigant extrusion..$^{22,25}$ Younger patients have loose cancellous bone and thin cortical plates that are susceptible to damage. For this reason, immature permanent teeth with necrotic dental pulp suffer from pain, swelling, and sinus tract development in the early stages of disease. A bone lesion can contribute to irrigant extrusion by reducing the resistance provided by periapical tissues ${ }^{27}$ resulting in an outcome similar to that caused by over-instrumentation. Hence, extrusion accidents may be more likely in teeth with non-vital pulps and periapical lesions according to Kleier et al. ${ }^{28}$ For this reason, treatment should be as conservative as possible. In the present study, a vial filled with distilled water was used to simulate a periapical bone lesion. The 25 gauge needle that functioned as an air vent in previous debris extrusion studies functioned here as a drain to collect the extruded irrigant.

Canal disinfection depends on irrigation with minimal to no instrumentation. Because the irrigation materials can be detrimental to SCAPs, irrigant extrusion should be minimized to prevent this deleterious effect. It was previously reported that the amount of apically extruded irrigant directly increases with an increase in the diameter of the apical constriction. ${ }^{29}$ However, the apical constriction was enlarged to a diameter of 0.2 and $0.4 \mathrm{~mm}$ that is only found in teeth with mature root morphologies. The finding in our study that there is a tendency to extrude more irrigant apically as the apical diameter is enlarged supports the findings of the previous study.

In this study, all root canals were irrigated with 10 $\mathrm{ml}$ of $2.5 \% \mathrm{NaOCI}$ solution via an endodontic syringe with a 27 gauge blunt needle that was placed in the root 2 or $4 \mathrm{~mm}$ short of the WL. In general, positioning of the needle farther away from the WL has been associated with reduced irrigant extrusion. ${ }^{30}$ This 
finding is in agreement with our study for a relatively narrow apical diameter. When the apical diameter was enlarged, the amount of irrigant extrusion increased regardless of the needle insertion depth.

\section{Conclusion}

Needle insertion depth had a significant effect on irrigant extrusion in simulated immature permanent

\section{References}

1. Lin LM, Pascon EA, Skribner J, Gangler P, Langeland K. Clinical, radiographic, and histologic study of endodontic treatment failures. Oral Surg Oral Med Oral Pathol. 1991 May;71(5):603-11.

2. Sjogren U, Hagglund B, Sundqvist G, Wing K. Factors affecting the long-term results of endodontic treatment. J Endod. 1990 Oct;16(10):498-504.

3. Zou L, Shen Y, Li W, Haapasalo M. Penetration of sodium hypochlorite into dentin. J Endod. 2010 May;36(5):793-6.

4. Andreasen JO, Farik B, Munksgaard EC. Long-term calcium hydroxide as a root canal dressing may increase risk of root fracture. Dent Traumatol. 2002 Jun;18(3):134-7.

5. Chen X, Bao ZF, Liu Y, Liu M, Jin XQ, Xu XB. Regenerative endodontic treatment of an immature permanent tooth at an early stage of root development: a case report. J Endod. 2013 May;39(5):719-22.

6. Torabinejad M, Turman M. Revitalization of tooth with necrotic pulp and open apex by using platelet-rich plasma: a case report. J Endod. 2011 Feb;37(2):265-8.

7. Nosrat A, Seifi A, Asgary S. Regenerative endodontic treatment (revascularization) for necrotic immature permanent molars: a review and report of two cases with a new biomaterial. J Endod. 2011 Apr;37(4):562-7.

8. Petrino JA, Boda KK, Shambarger S, Bowles WR, McClanahan SB. Challenges in regenerative endodontics: a case series. J Endod. 2010 Mar;36(3):536-41.

9. Kim DS, Park HJ, Yeom JH, Seo JS, Ryu GJ, Park KH, et al. Long-term follow-ups of revascularized immature necrotic teeth: three case reports. Int J Oral Sci. 2012 Jun;4(2):109-13.

10. Galler KM, D'Souza RN, Federlin M, Cavender AC, Hartgerink JD, Hecker S, et al. Dentin conditioning codetermines cell fate in regenerative endodontics. J Endod. 2011 Nov;37(11):1536-41.

11. Trevino EG, Patwardhan AN, Henry MA, Perry G, DybdalHargreaves N, Hargreaves KM, et al. Effect of irrigants on the survival of human stem cells of the apical papilla in a platelet-rich plasma scaffold in human root tips. J Endod. 2011 Aug;37(8):1109-15.

12. Behrents KT, Speer ML, Noujeim M. Sodium hypochlorite accident with evaluation by cone beam computed tomography. Int Endod J. 2012 May;45(5):492-8. teeth depending on the apical diameter. There was a tendency to extrude more irrigant through the periapical area as the apical diameter increased. For this reason, every effort should be exerted to limit periapical extrusion of materials during treatment. To avoid this phenomenon, we recommended irrigating cautiously and with low pressure while ensuring that the excess irrigant leaves the root canal via the access cavity.

13. Gernhardt CR, Eppendorf K, Kozlowski A, Brandt M. Toxicity of concentrated sodium hypochlorite used as an endodontic irrigant. Int Endod J. 2004 Apr;37(4):272-80.

14. Hulsmann M, Hahn W. Complications during root canal irrigation--literature review and case reports. Int Endod J. 2000 May;33(3):186-93.

15. Serper A, Ozbek M, Calt S. Accidental sodium hypochloriteinduced skin injury during endodontic treatment. J Endod. 2004 Mar;30(3):180-1.

16. Sonoyama W, Liu Y, Yamaza T, Tuan RS, Wang S, Shi S, et al. Characterization of the apical papilla and its residing stem cells from human immature permanent teeth: a pilot study. J Endod. 2008 Feb;34(2):166-71.

17. Psimma Z, Boutsioukis C, Kastrinakis E, Vasiliadis L. Effect of needle insertion depth and root canal curvature on irrigant extrusion ex vivo. J Endod. 2013 Apr;39(4):521-24.

18. Seltzer S, Naidorf IJ. Flare-ups in endodontics: I. Etiological factors. J Endod. 2004 July;30(7):476-81.

19. Ferraz CC, Gomes NV, Gomes BP, Zaia AA, Teixeira FB, Souza-Filho FJ. Apical extrusion of debris and irrigants using two hand and three engine-driven instrumentation techniques. Int Endod J. 2001 Jul;34(5):354-8.

20. Kustarci A, Akdemir N, Siso SH, Altunbas D. Apical extrusion of intracanal debris using two engine driven and stepback instrumentation techniques: an in-vitro study. Eur J Dent. 2008 Oct;2(4):233-9.

21. Madhusudhana K, Mathew VB, Reddy NM. Apical extrusion of debris and irrigants using hand and three rotary instrumentation systems - an in vitro study. Contemp Clin Dent. 2010 Oct;1(4):234-6.

22. Altundasar E, Nagas E, Uyanik O, Serper A. Debris and irrigant extrusion potential of 2 rotary systems and irrigation needles. Oral Surg Oral Med Oral Pathol Oral Radiol Endod. 2011 Oct;112(4):e31-5.

23. Ghivari SB, Kubasad GC, Chandak MG, Akarte N. Apical extrusion of debris and irrigant using hand and rotary systems: a comparative study. J Conserv Dent. 2011 Apr;14(2):187-90.

24. Boutsioukis C, Psimma Z, van der Sluis LW. Factors affecting irrigant extrusion during root canal irrigation: a systematic review. Int Endod J. 2013 Jul;46(7):599-618. 
25. Tasdemir T, Er K, Celik D, Yildirim T. Effect of passive ultrasonic irrigation on apical extrusion of irrigating solution. Eur J Dent. 2008 Jul;2(3):198-203.

26. Desai P, Himel V. Comparative safety of various intracanal irrigation systems. J Endod. 2009 Apr;35(4):545-9.

27. Vier FV, Figueiredo JA. Prevalence of different periapical lesions associated with human teeth and their correlation with the presence and extension of apical external root resorption. Int Endod J. 2002 Aug;35(8):710-9.
28. Kleier DJ, Averbach RE, Mehdipour O. The sodium hypochlorite accident: experience of diplomates of the American Board of Endodontics. J Endod. 2008 Nov;34(11):1346-50.

29. Tinaz AC, Alacam T, Uzun O, Maden M, Kayaoglu G. The effect of disruption of apical constriction on periapical extrusion. J Endod. 2005 Jul;31(7):533-5.

30. George R, Walsh LJ. Apical extrusion of root canal irrigants when using Er:YAG and Er,Cr:YSGG lasers with optical fibers: an in vitro dye study. J Endod. 2008 Jun;34(6):706-8. 